\title{
Effect of Gas Flow Rate on the Solubility and Lifetime of Liquid-Rotated Aerator Generated-Microbubbles
}

\author{
Nur Farida Amalia ${ }^{1} \quad$ Sera Budi Verinda ${ }^{2} \quad$ Eva Sasmita $^{3} \quad$ Eko Yulianto $^{3} \quad$ Sumariyah $^{1}$ \\ Gunawan $^{4} \quad$ Muhammad Nur ${ }^{1,3 *}$ \\ 1.Magister of Physics, Physic Department, Faculty of Science and Mathematics, Diponegoro University, \\ Semarang \\ 2.Magister of Biomedicine, Faculty of Medicine, Diponegoro University, Semarang \\ 3.Center for Plasma Research, Faculty of Science and Mathematics, Diponegoro University, Semarang \\ 4.Chemistry Department, Faculty of Science and Mathematics, Diponegoro University, Semarang
}

\begin{abstract}
Ozone was adopted to be an alternative technology for the elimination of various kinds of micropollutants. However, ozonation is still limited by poor ozone dissolution in water. Microbubble technology was proposed to overcome this limitation. This paper was aimed to investigate the effect of inlet gas flow rate on the production and solubility of ozone in the liquid phase. A double dielectric barrier discharge (DDBD) -based ozone generator was used and connected to a microbubble aerator. Ozone concentration was measured both in outlet points and in water under various inlet gas flow rates. In addition, the lifetime of best-ozonated micro-bubbles (OMB) was investigated by storing them at two different temperatures. The application of a lower inlet gas flow rate increased ozone concentration, which can increase the mass of ozone input in the water resulted in better ozone solubility. Furthermore, the size of generated bubbles was known to be finer as the decrease of inlet gas flow rates. Lastly, we got that OMB water stored at lower temperatures resulted in longer retention time than the warmer one.
\end{abstract}

Keywords: Ozone, gas flow rate, solubility, ozone lifetime, microbubble

DOI: $10.7176 /$ APTA/85-02

Publication date: November $30^{\text {th }} 2021$

\section{Introduction}

The removal of micropollutants in wastewater becomes increasingly important. The secondary effluent from the wastewater treatment plant usually discharged into urban rivers contains a lot of refractory organic pollutants that are inefficiently removed during conventional wastewater treatment methods. Ozone was known as a powerful oxidant, that widely used as an advanced wastewater treatment process. Ozone shows great performance in eliminating various persistent micropollutants through a process called ozonation [1].

Ozone can be generated by exciting oxygen molecules in a double dielectric barrier discharge (DDBD) which was known to produce higher purity of ozone compared to single dielectric barrier discharge (SDBD), this was due to the structure of DDBD itself which enable it to prevent inlet gas to be contaminated by its electrodes. Unfortunately, the ozonation performance is severely limited by its poor solubility in water, which is $1.0 \times 10^{-6}$ $\mathrm{mol} / \mathrm{m}^{3} \mathrm{~Pa}$ to $1.3 \times 10^{-4} \mathrm{~mol} / \mathrm{m}^{3} \mathrm{~Pa}$ [2]. In addition, the half-life of ozone in distilled water is known to be quite short, about 20-30 minutes at $20^{\circ} \mathrm{C}$ and will decrease with increasing temperature [3].

Micro-bubbles technology was proposed to overcome these problems. Micro-bubbles are defined as bubbles having a diameter in a range of $1 \mu \mathrm{m}-100 \mu \mathrm{m}$ (ISO 2017) [4], which can enhance the gas mass transfer efficiency in a liquid phase. Bubbles having a diameter of $110 \mu \mathrm{m}$ are capable to rise up volumetric mass transfers coefficient until 100 times higher than macro bubbles [5]. Moreover, hydroxyl radicals are produced when the microbubble interface suddenly disappears. This condition can be an added advantage for eliminating recalcitrant pollutants in water [6].

Various techniques were developed to efficiently generating-bubbles such as rotary ventury type, electrostatic spraying, ultrasonic system, liquid flow type, etc [7]. Thus, In this work, a DDBD ozone generator has been investigated by characterizing the effects of inlet gas flow rates toward ozone concentration and ozone yield, also their correlation with ozone solubility under a liquid flow type based-aerator system. Furthermore, the OMB retention time in the water was also studied.

\section{Methods}

\subsection{Treatment and Sampling Technique}

In this study, ozone was generated by a double dielectric barrier discharge (DDBD). Oxygen was used as the input gas. The voltage was maintained at $2.6 \mathrm{kV}$ and the oxygen flow rate was varied from $0.1 \mathrm{~L} / \mathrm{min}$ to 0.5 $\mathrm{L} / \mathrm{min}$. The produced ozone by the DDBD generator was injected continuously into $10 \mathrm{~L}$ of distilled water for 90 minutes using different inlet oxygen flow rates. The water temperature was monitored between 25 to $27{ }^{\circ} \mathrm{C}$ 
during the experiments. Figure 1 shows a schematic representation of this experimental setup. $10 \mathrm{~mL}$ samples of dissolved ozone measurement were taken every 15 minutes, meanwhile, $150 \mathrm{~mL}$ samples of stored ozone were collected post-treatment only.

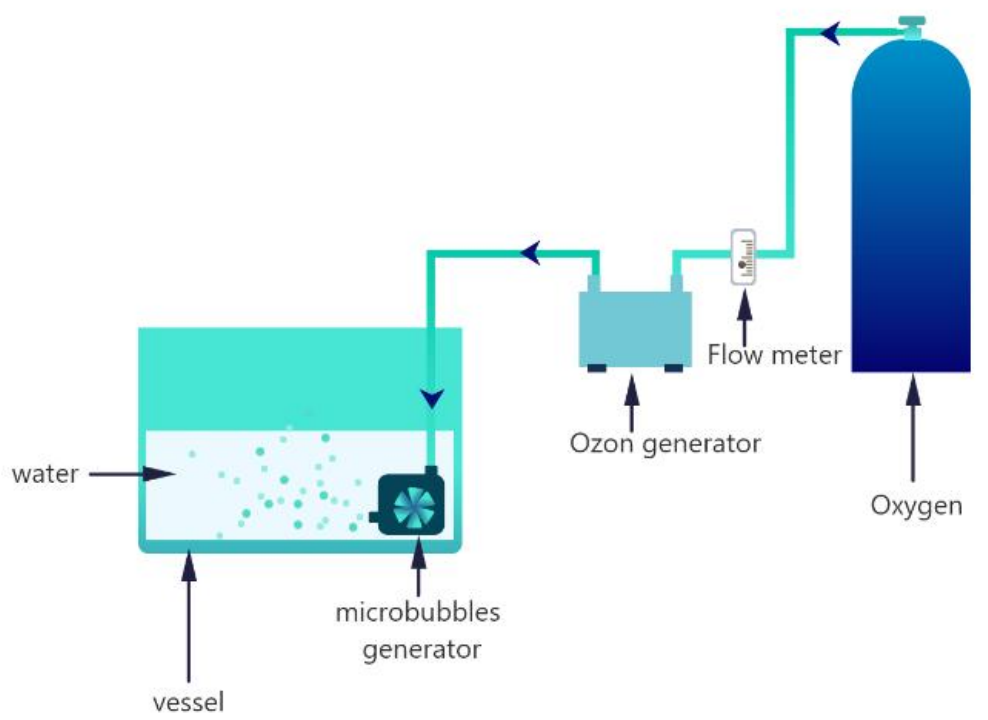

Figure 1. Experimental setup design

\subsection{The Measurement of Produced Ozone}

Ozone concentration $\left(\mathrm{C}_{\mathrm{O}_{3}}\right)$ was calculated using the iodometry method and follows the below equation [8] (Nur et al. 2019), and then the ozone capacity was calculated by multiplying $C_{O_{3}}$ with the corresponding flow rates [9].

$$
C_{0_{3}}=\frac{R \times V_{t} \times N_{t}}{V_{\text {inlet oxygen }}}
$$

$C_{0_{3}}$ is the concentration of produced ozone $(\mathrm{gram} / L), V_{t}$ is the titrant $\left(\mathrm{Na}_{2} \mathrm{~S}_{2} \mathrm{O}_{3}\right)$ volume $(L), N_{t}$ is the normality of titrant $\left(\mathrm{Na}_{2} \mathrm{~S}_{2} \mathrm{O}_{3}\right) 0.4 \mathrm{M}, V_{\text {inlet oxygen }}$ is the total volume of injected oxygen (L) into KI $0,2 \mathrm{M}$ solution.

\subsection{The Measurement of Ozone Dissolution}

Micro-bubble was generated using a self-made liquid-rotating micro-bubble aerator. The micro-bubble generator consisting of a propeller to rotate inlet water at high speed around its axis and was placed in the bottom of a container. The inlet ozone was positioned perpendicularly to the axis of rotating inlet water. Such type of aerator produces micro-bubbles by pressuring air-saturated water toward a modified nozzle, and then release it into the container [10]. Dissolved ozone $\left(D_{O_{2}}\right)$ was measured using Spectroquant ${ }^{\circledR}$ Move DC (173635) - ozone test kit (Merck KGaA, Germany).

\subsection{The study of ozone decomposition in distilled water}

Ozonated micro-bubbles-water was stored in two different temperatures, which were room temperature $\left(26-27^{\circ} \mathrm{C}\right)$ and cooler temperature $\left(3-4^{\circ} \mathrm{C}\right)$ in a plastic bottles. Both of the two groups had the same initial ozone concentrations $(0.36 \mathrm{ppm})$. The decomposition of ozone was examined in distilled water each day for three days. 


\section{Results}

\subsection{The effect of Flow rate in Ozone Concentration}

The characterization of the ozone generator was carried out using a high voltage AC source of $2.6 \mathrm{kV}$. In the ozone formation process, this high power is needed to facilitate the dissociation process (R-1) to produce $\mathrm{O}$ atoms. Then with the help of neutral atoms, these $\mathrm{O}$ atoms are recombined in a three-body process $(\mathrm{R}-2)$ to produce ozone $[11,12]$.

$$
\begin{aligned}
& e^{-}+\mathrm{O}_{2} \rightarrow 2 \mathrm{O}+e^{-} \\
& \mathrm{O}+\mathrm{O}_{2}+\mathrm{O}_{2} \rightarrow \mathrm{O}_{3}+\mathrm{O}_{2}
\end{aligned}
$$

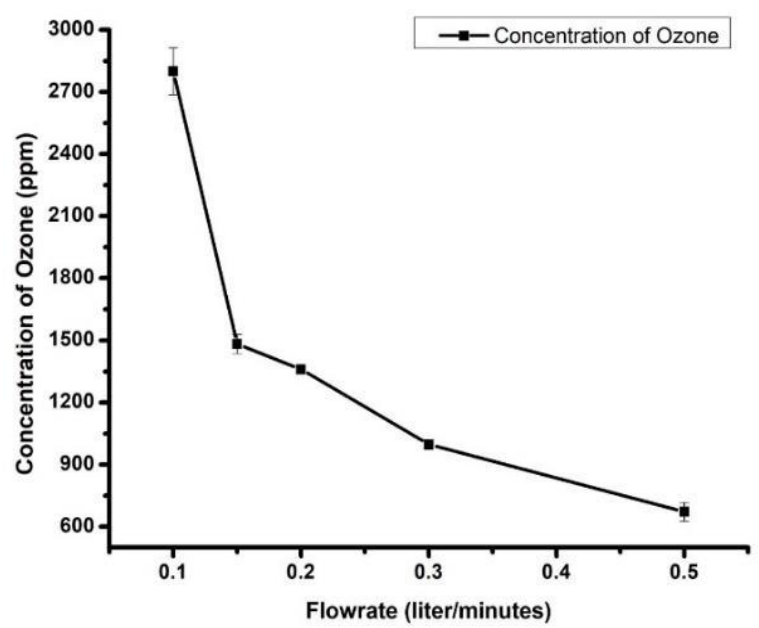

Figure 2. Ozone concentration as a function of flow rate

The effect of oxygen flow rate on ozone concentration is given by Figure 2. The maximum ozone concentration of $2800 \mathrm{ppm}$ was obtained when the oxygen flow rate was $0.1 \mathrm{~L} /$ minute while the lowest value of $812.8 \mathrm{ppm}$ was obtained when the oxygen flow rate of $0.5 \mathrm{~L} /$ minute. A decrease in the input gas flow rate results in a higher concentration of ozone. On the other hand, an increase in the gas flow rate results in lower ozone production.

The high gas flow rate causes the residence time of the oxygen in the DDBD gap to shorten, which means the contact time between oxygen and electrons decreases. The $\mathrm{O}$ atoms resulting from the dissociation process also come out faster along with a high gas flow rate. As a result, the number of $\mathrm{O}$ atoms available in the reactor is small, while these $\mathrm{O}$ atoms are needed for the three-body process to take place. This is what causes relatively small ozone production at high gas flow rates $[9,13]$.

Ozone capacity is defined as the amount of produced ozone in a given time. Figure 3 shows ozone capacity that is proportional to the input gas flow rate. This chart shows an uptrend, but at the point of $0.15 \mathrm{~L} / \mathrm{min}$ the corresponding ozone capacity drops. The maximum ozone capacity was $24.38 \mathrm{~g} / \mathrm{h}$ when the input gas flow was $0.5 \mathrm{~L} / \mathrm{min}$. Wei et al [14] found that the higher flow rate leading to the decrement of input gas temperature enabling the generator to achieve maximum capacity.

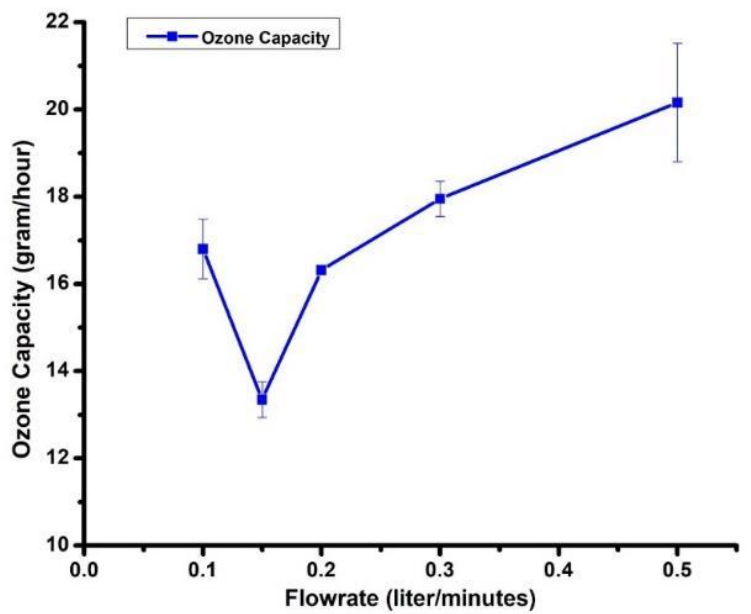

Figure 3. ozone capacity as a function of flow rate 


\subsection{Effect of Oxygen Flow Rate On The Dissolved Ozone}

The concentrations of the dissolved ozone in water were plotted against time as seen in Figure. 4. Solid lines are the Boltzmann fit results. For a given constant gas flow rate, the dissolved ozone increase with aeration times goes by until reaching the equilibrium state. The equilibrium of ozone concentration in water increase with the decreasing gas flow rate from $0.5 \mathrm{~L} / \mathrm{min}$ to $0.1 \mathrm{~L} / \mathrm{min}$. This is due to higher ozone production at lower gas streams which increases the ozone mass input for aeration. This result is similar to the previous study by Wei et al., (2017) that the dissolved ozone concentration was found to be proportional to the incoming ozone concentration.

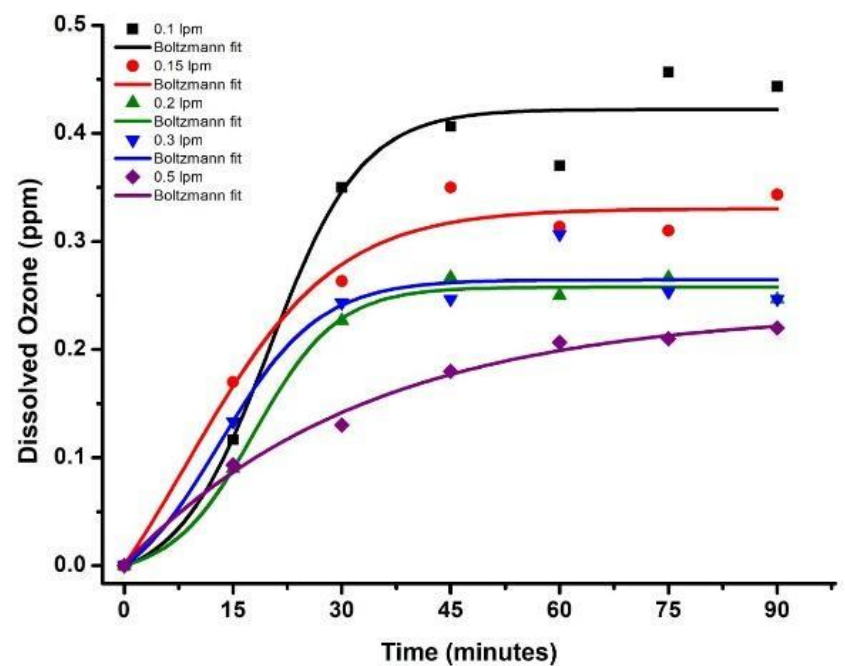

Figure 4. The effect of gas flow rate on the dissolved ozone concentration (pH 7.0; temp. $\left.25 \pm 1{ }^{\circ} \mathrm{C}\right)$

The gas flow rate also affects the size of the bubbles in the water. Higher gas flow rates produce larger bubbles. The larger the bubble size, the smaller the total surface area and bubble density, as a result the gasliquid mass transfer decreases [7]. While [5] found that the average bubble size radius of the different air streams, between $1 \mathrm{~L} / \mathrm{min}$ and $0.25 \mathrm{~L} / \mathrm{min}$, was the same. However, the number of microbubbles is greater at lower gas flow rates [5].

In addition to the input ozone concentration and bubble diameter, the solubility of ozone is also significantly affected by other factors such as temperature, $\mathrm{pH}$, the electrical conductivity of the medium, and the presence of impurities [15].

\subsection{Kinetic Decomposition}

The OMB decomposition in water was plotted against time for two different storage conditions, which were the cold temperature $\left(3-4^{\circ} \mathrm{C}\right)$ and room temperature $\left(26-27^{\circ} \mathrm{C}\right)$ as illustrated by Figure 5 . The fitted results are based on exponential equation for fitting (cooler temperature $\left(R^{2}=0.999\right)$ and room temperature $\left(R^{2}=1\right)$ ).

After three days, the ozone concentration left was $0.067 \mathrm{ppm}$ and $0.06 \mathrm{ppm}$ at cold temperature and room temperature respectively The ozonated water exhibited faster decay mechanism when stored at room temperature than the other group. The ozone lifetime in water could be prolonged by increasing the acidity of the water (Egorova et al. 2015). From these results, there is the potential for Micro Bubbles to prolong the binding time of ozone in the water. Although it still needs to be improved again to be used for many applications. 


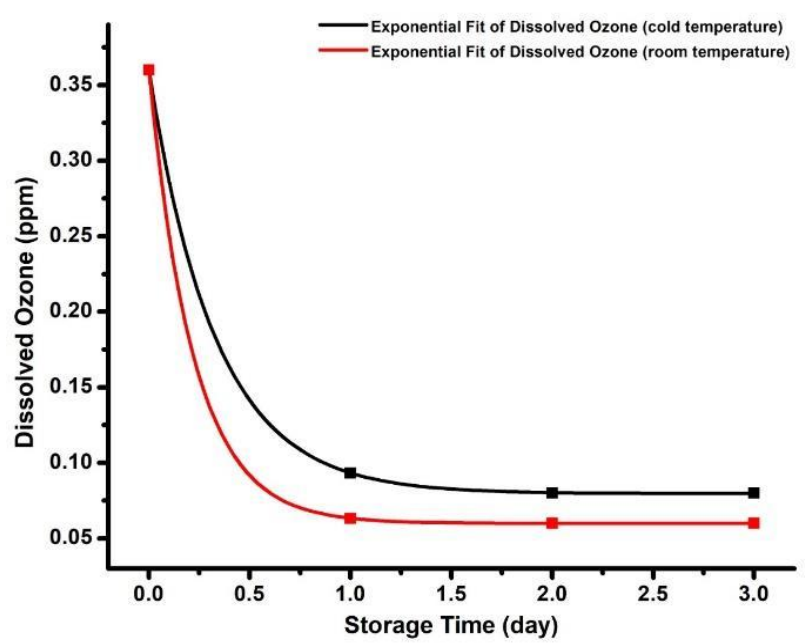

Figure 5. Kinetics of ozone decomposition in cooler temperature $\left(3-4^{\circ} \mathrm{C}\right)$ and room temperature $\left(26-27^{\circ} \mathrm{C}\right)$.

\section{Conclusion}

The lower flow rate of input gas led to the higher ozone concentration. This phenomenon was in reverse with ozone capacity that tends to be smaller with the decrement of input gas flow rate. In the case of dissolved ozone in water, the lower oxygen flow rate might reduce the size of the bubbles, giving better mass transfers. Increasing ozone concentration injected into water might rise ozone mass input and lead to scaling up total dissolved ozone. The ozonated micro-bubbles stored in colder temperatures were known to stay longer than those stored in room temperatures.

\section{Acknowledgment}

The research team would like to thank the Masters Education towards Doctorate for Superior Bachelors (PMDSU) Universitas Diponegoro for Research Funding for Fiscal Year 2021 according to the sharing facilities for supporting this research.

\section{References}

[1] Cuerda-correa, E. M., Alexandre-franco, M. F., and Fern, C., 2020. Antibiotics from Water. An Overview. Water, 12, 1-50.

[2] Azuma, T., Otomo, K., Kunitou, M., Shimizu, M., Hosomaru, K., Mikata, S., Mino, Y., and Hayashi, T., 2019. Removal of pharmaceuticals in water by introduction of ozonated microbubbles. Separation and Purification Technology, 212 (September 2018), 483-489.

[3] Cullen, P. J., Tiwari, B. K., O’Donnell, C. P., and Muthukumarappan, K., 2009. Modelling approaches to ozone processing of liquid foods. Trends in Food Science and Technology [online], 20 (3-4), 125-136. Available from: http://dx.doi.org/10.1016/j.tifs.2009.01.049.

[4] ISO, 2017. Iso/tr 23015:2020 [online]. Available from: https://www.iso.org/standard/74323.html?browse=tc [Accessed 16 Feb 2021]

[5] Alam, H. S., Redhyka, G. G., Bahrudin, Sugiarto, A. T., Salim, T. I., and Mardhiya, I. R., 2018. Design and performance of swirl flow microbubble generator. International Journal of Engineering and Technology(UAE), 7 (4), 66-69.

[6] Takahashi, M., Chiba, K., and Li, P., 2007. Free-radical generation from collapsing microbubbles in the absence of a dynamic stimulus. Journal of Physical Chemistry B, 111 (6), 1343-1347.

[7] Haris, S., Qiu, X., Klammler, H., and Mohamed, M. M. A., 2020. The use of micro-nano bubbles in groundwater remediation: A comprehensive review. Groundwater for Sustainable Development [online], 11 (March), 100463. Available from: https://doi.org/10.1016/j.gsd.2020.100463.

[8] Nur, M., Yulianto, E., Kinandana, A. W., Restiwijaya, M., and Arianto, F., 2019. Development of DDBD and plasma jet reactors for production reactive species plasma chemistry Development of DDBD and plasma jet reactors for production reactive species plasma chemistry. IOP Conf. Series: Materials Science and Engineering, 509 (May), 8

[9] Chasanah, U., Yulianto, E., Zain, A. Z., Sasmita, E., Restiwijaya, M., Kinandana, A. W., Arianto, F., and Nur, M., 2019. Evaluation of Titration Method on Determination of Ozone Concentration produced by Dielectric Barrier Discharge Plasma (DBDP) Technology. Journal of Physics: Conference Series, 1153 (1). 
[10] Han, M., Park, Y., Lee, J., and Shim, J., 2002. Effect of pressure on bubble size in dissolved air flotation. Water Science and Technology: Water Supply, 2 (5-6), 41-46.

[11] Fridman, A., 2008. Plasma Chemistry. New York: Cambridge University Press.

[12] Nur, M., Susan, A. I., Muhlisin, Z., Arianto, F., and Wibowo, A., 2017. Evaluation of Novel Integrated Dielectric Barrier Discharge Plasma as Ozone Evaluation of Novel Integrated Dielectric Barrier Discharge Plasma as Ozone Generator. Bulletin of Chemical Reaction Engineering \& Catalysis, 1 (January),

[13] Rahardian, A., Masfufah, M., Maftuhah, S., Yulianto, E., Sumariyah, S., and Nur, M., 2020. Effective medical ozone production using mesh electrodes in double dielectric barrier type plasma generators. AIP Conference Proceedings, 2197 (January)

[14] Wei, L., Deng, Q., and Zhang, Y., 2020. Ozone generation enhanced by silica catalyst in oxygen-fed dielectric barrier discharge. Vacuum, 173 (December 2019), 1-8.

[15] Egorova, G. V., Voblikova, V. A., Sabitova, L. V., Tkachenko, I. S., Tkachenko, S. N., and Lunin, V. V., 2015. Ozone Solubility in Water. Moscow University Chemistry Bulletin, 70 (5), 207-210.

[16] Wei, C., Zhang, F., Hu, Y., Feng, C., and Wu, H., 2017. Ozonation in water treatment: The generation, basic properties of ozone and its practical application. Reviews in Chemical Engineering, 33 (1), 49-89. 